EESTI NSV TEADUSTE AKADEEMIA TOIMETISED. XII KOIDE FOOSIKA-, MATEMAATIKA- JA TEHNIKATEADUSTE SEERIA. 1963, NR. 1

НЗВЕСТИЯ АКАДЕМИН НАУК ЭСТОНСКОК ССР. ТОМ ХІІ СЕРНЯ ФИЗНКО-МАТЕМАТИЧЕСКИХ И ТЕХНИЧЕСКИХ НАУК. 1963, № I

\title{
ОБ ИСПОЛЬЗОВАНИИ СЛАНЦЕЗОЛЬНЫХ ШЛАКОВ В КАЧЕСТВЕ СТРОИТЕЛЬНОГО ВЯЖУЩЕГО
}

\author{
И. ЛАСН
}

\section{Н. ДИЛАКТОРСКИИ,}

\author{
доктор геолого-минералогических наук
}

Жилкое шлакоудаление прн сжигании таких многозольных топлив, какими являются прибалтийские горючне сланцы, может быть выгодным только при условии полноценного использования шлаков, образующихся в топке при расплавлении минеральной составляющей сланца. В связи с этим возникла необходимость решения вопроса о возможности применения будущих промышленных «отходов» - сланщезольных шлаков - в качестве сырья для изготовления строительных материалов и отбора для практического использования тех из них, которые будут удовлетворять по свонм свойствам как энергетиков так и стронтелей.

В данной статье описываются опыты, проведенные нами для установления зависимости гидравлической активности и температуры жидкотекучего состояния сланцезольных шлаков от их химического состава. Исследована возможность применения сланцезольных шлаков как для изготовления бетона автоклавной обработки, так и в шлакопортланд-цементе с различным содержанием клинкера и гипса при твердении в нормальных условнях.

\section{1. Методы исследования}

Сланцезольные шлаки изготовлялись в лабораторных условиях плав лением сланцевой золы в ацетилено-кислородном пламени с последующей мокрой грануляцией расплава. Температуры жидкотекучего состояния шлаков измерялись оптическим пирометром в момент отрыва капли от палочки, формованной из сланцевой золы. Гидравлическая активность шлака оценивалась на основе прочности получаемого из него шлакопортланд-цемента. Шлак и портланд-цементный клинкер размалывались отдельно, а затем смешивались в шаровой мельнице. Кубики, раз мером $3 \times 3 \times 3 \mathrm{~cm}$ *, формовались пластичным методом из раствора $1: 3$ и хранились при температуре $20^{\circ} \mathrm{C}$ в атмосфере, насыщенной водя ным паром. Образцы извлекались из форм через 3 дня после изготовления. Для определения коэффициента перехода от прочности куо̆икон $3 \times 3 \times 3$ cм пластичной формовки, выдержанных во влажном воздухе, к прочности трамбованных кубиков $7 \times 7 \times 7$ cм, выдержанных в воде (по ГОСТ $310-\div 1$ ), были изготовлены соответствующие серии образцов из портланд-цемента. Прочность на сжатие и коэффициенты перехода для использованных портланд-цементных клинкеров ПЦ-1 и ПЦ-2 при ведены в табл. 1.

* Малые, количества имевшихся в нашем распоряжении шлаков не позволяли пзготовлять кубики размером $7 \times 7 \times 7 \mathrm{~cm}$. 
таблица I

Прочность на сжатие и коэффициенты перехода (К) для портланд-цемента

\begin{tabular}{|c|c|c|c|c|c|}
\hline \multirow[t]{2}{*}{ Цемент } & \multirow{2}{*}{$\begin{array}{c}\text { Характеристика } \\
\text { кубнков }\end{array}$} & \multirow{2}{*}{$\begin{array}{c}\text { Коли- } \\
\text { чество } \\
\text { воды } \\
\text { затво- } \\
\text { рения, } \\
\% \\
\end{array}$} & \multicolumn{3}{|c|}{$\begin{array}{c}\text { Прочность на сжатие (R) } \\
\text { в } \kappa \Gamma / \text { с }^{2} \text { образцов в } \\
\text { возрасте }\end{array}$} \\
\hline & & & 3 дня & 7 днеӥ & 28 дней \\
\hline \multirow{2}{*}{ ПЦ-1 } & $\begin{array}{l}7 \times 7 \times 7, \text { трамб. } \\
3 \times 3 \times 3, \text { пласт. }\end{array}$ & $\begin{array}{r}8,0 \\
18,5\end{array}$ & $\begin{array}{r}224,5 \\
56,3\end{array}$ & $\begin{array}{l}338 \\
119,1\end{array}$ & $\begin{array}{l}418 \\
190,7\end{array}$ \\
\hline & $\mathrm{K}=\frac{\mathrm{R} \text { трамб. }}{\mathrm{R} \text { пласт. }}$ & & 4 & 2,8 & 2,19 \\
\hline \multirow{2}{*}{ ПЦ-2 } & $\begin{array}{l}7 \times 7 \times 7, \text { трамб. } \\
3 \times 3 \times 3, \text { пласт. }\end{array}$ & $\begin{array}{r}8,2 \\
16,5\end{array}$ & $\begin{array}{l}227 \\
56.8\end{array}$ & $\begin{array}{l}300 \\
116\end{array}$ & $\begin{array}{l}384 \\
181\end{array}$ \\
\hline & $\mathrm{K}=\frac{\mathrm{R} \text { трамб. }}{\mathrm{R} \text { пласт. }}$ & & 4 & 2,58 & 2,12 \\
\hline
\end{tabular}

Таблица 2

Характеристика сланцезольных шлаков и портланд-цементного клинкера

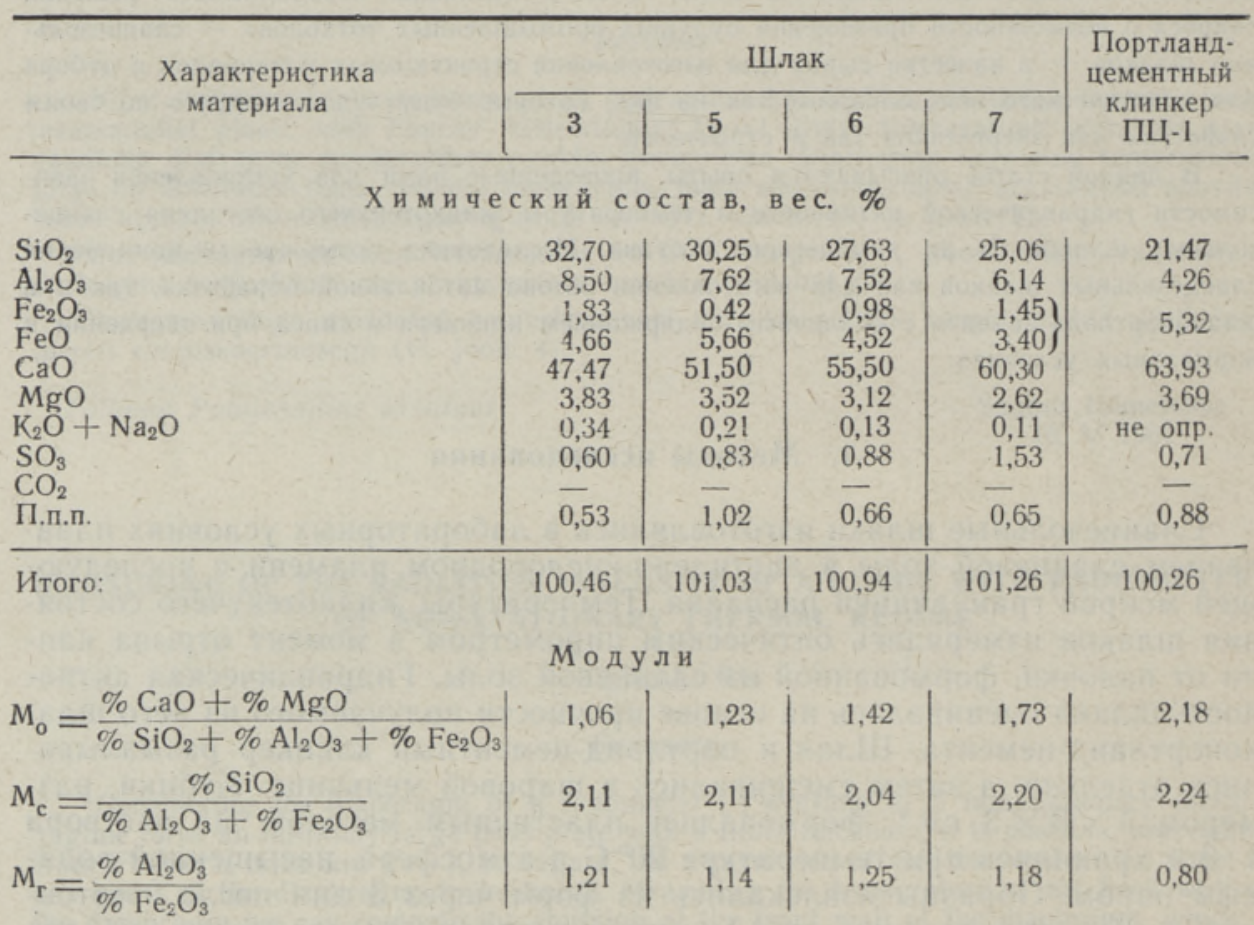

Содержание отд'ельных минералов, \%

Алит $\left(3 \mathrm{CaO} \cdot \mathrm{SiO}_{2}\right)$

Белит $\left(2 \mathrm{CaO} \cdot \mathrm{SiO}_{2}\right)$
55

16

Тонина помола

Удельная поверхность, $с м^{2} / 2$

\begin{tabular}{l|l|l|l|}
3440 & 3520 & 3340 & 3320
\end{tabular}

Примеч ни ие: Химические анализы выполнены химиком-аналитиком Л. Тамм. 


\section{2. Активность шлака в зависимости от его состава}

Первая серия опытов была проведена для выяснения зависимости активности шлака от его химического состава, а также для предварительного установления марки получаемого шлакопортланд-цемента.

Химические и минералогические составы использованных шлаков и портланд-цементного клинкера приведены в табл. 2. У шлака ИЭ, полученного в опытной топке Института энергетики АН ЭССР, определено только содержание $\mathrm{CaO}(35,84 \%)$.

Шлаки размалывались до удельной поверхности, около $3400 \mathrm{~cm}^{2} / 2$ по Товарову, и смешивались с измельченным портланд-цементным клинкером. Содержание клинкера ПЦ-1 в шлакопортланд-цементе $20 \%$. Результаты испытания кубиков $3 \times 3 \times 3$ см приведены в табл. 3.

Таблица 3

Прочность на сжатие образцов из шлакопортланд-цемента

\begin{tabular}{|c|c|c|c|c|c|}
\hline \multirow{3}{*}{$\begin{array}{l}\text { Шлакопорт- } \\
\text { ланд-цемент }\end{array}$} & \multirow{3}{*}{$\begin{array}{c}\text { Количество } \\
\text { воды затво- } \\
\text { рения, \% }\end{array}$} & \multicolumn{4}{|c|}{ Прочность на сжатие } \\
\hline & & \multicolumn{3}{|c|}{ в $\kappa \Gamma / c M^{2}$ в возрасте } & \multirow{2}{*}{$\begin{array}{c}\text { Расчет- } \\
\text { ная мар- } \\
\text { ка цемен- } \\
\text { та*** }^{* *}\end{array}$} \\
\hline & & 7 дней & 28 дней & 56 дней & \\
\hline ИЭ-20* & 13,0 & 11,7 & 21,3 & 25 & 47 \\
\hline $3-20$ & 13,5 & 21,0 & 97,2 & 152 & 213 \\
\hline $5-20$ & 14,25 & 1,9 & 43,1 & 55 & 94 \\
\hline $6-20$ & 15,0 & 9,6 & 46,5 & 72,5 & 102 \\
\hline $7-20$ & 18,5 & 13,9 & 93,1 & 153,4 & 204 \\
\hline
\end{tabular}

* Цифра за обозначением шлака показывает содержание клинкера в-составе шлакопортланд-цемента.

** Получена при умножении прочности в возрасте 28 дней на переходный коэффициент $\mathrm{K}_{28}=2,19$.

Из приведенных в табл. 2 и 3 данных видно, что полученные шлакопортланд-цементы имеют низкую прочность, особенно после 7 дней твердения. Более активными при нормальном твердении являются шлаки с содержанием окиси кальция $40-50 \%$ или выше $58 \%$ (в последнем случае получается т. н. плавленый цемент).

\section{3. Изучение возможности повышения прочности шлакопортланд-цемента}

По данным предварительных опытов выяснилось, что для производства шлакопортланд-цемента наибольший интерес представляют шлаки, содержащие менее $50 \%$ окиси кальщия. Поэтому дальнейшие исследования были проведены именно с этими шлаками. С целью повышения недостаточной прочности шлакопортланд-цементов, особенно в первые сроки твердения, изучалось влияние различных количеств портланд-цементного клинкера и двуводного гипса при более тонком помоле шлака (удельная поверхность около $4000 \mathrm{~cm}^{2} / 2$ ). Характеристика использованных исходных материалов приведена в табл. 4.

Для выбора оптимального соотношения между шлаком и клинкером, из шлака № 2 были изготовлены шлакопортланд-цементы, содержав- 
шие 40, 25 и 15\% клинкера. Двуводный гипс добавлялся в количестве 2 , 5 и $8 \%$ от веса шлакопортланд-цемента (свыше 100\%).

Результаты физико-механических испытаний кубиков $3 \times 3 \times 3$ cм приведены в табл. 5 . Из них следует, что прочность шлакопортланд-цемента после 7 дней твердения увеличивается по мере повышения содержания клинкера и гипса. В начальном периоде твердения больше влияет добавка гипса. Прочность шлакопортланд-цементов, содержащих 5 и $8 \%$ гипса, к 7 дню превышает прочность использованного портланд-цемента ПЦ-2, у которого $\mathrm{R}_{7}=116$ (см. табл. 1). К 28 дням твердения прочность всех шлакопортланд-цементов превышает прочность портландцемента $\left(\mathrm{R}_{\text {пц } 28}=181\right)$. Через 56 дней твердения шлакопортландцементы, содержащие 15 и 25\% портланд-цементного клинкера, имеют максимальную прочность при добавке $2 \%$ гипса, шлакопортланд-цементы с $40 \%$ клинкера - при добавке $5 \%$ гипса.

Таблица 4

Характеристика сланцезольных шлаков и портланд-цементного клинкера

\begin{tabular}{|c|c|c|c|c|c|}
\hline \multirow{2}{*}{$\begin{array}{c}\text { Характеристика } \\
\text { материала }\end{array}$} & \multicolumn{4}{|c|}{ Шлак } & \multirow{2}{*}{$\begin{array}{c}\text { Портланл- } \\
\text { цементный } \\
\text { клинкер } \\
\text { ПЦ-2 }\end{array}$} \\
\hline & 1 & 2 & 4 & MBTY* & \\
\hline
\end{tabular}

Химический состав, вес. \%

\begin{tabular}{|c|c|c|c|c|c|}
\hline $\begin{array}{l}\mathrm{SiO}_{2} \\
\mathrm{Al}_{2} \mathrm{O}_{3} \\
\mathrm{Fe}_{2} \mathrm{O}_{3} \\
\mathrm{FeO} \\
\mathrm{CaO} \\
\mathrm{MgO} \\
\mathrm{K}_{2} \mathrm{O}+\mathrm{Na}_{2} \mathrm{O} \\
\mathrm{SO}_{3} \\
\mathrm{CO}_{2} \\
\text { П.п.п. }\end{array}$ & $\begin{array}{r}36,09 \\
7,77 \\
1,74 \\
4,87 \\
42,65 \\
4,21 \\
1,98 \\
0,87 \\
- \\
-\end{array}$ & $\begin{array}{r}35,47 \\
8,31 \\
2,42 \\
3,75 \\
44,18 \\
4,40 \\
1,57 \\
0,32 \\
-\end{array}$ & $\begin{array}{r}33,40 \\
7,80 \\
1,67 \\
4,10 \\
48,35 \\
4,20 \\
0,98 \\
0,26 \\
- \\
-\end{array}$ & $\begin{array}{r}37,36 \\
8,97 \\
3,14 \\
2,58 \\
39,46 \\
5,10 \\
3,30 \\
0,24 \\
0,22 \\
-\end{array}$ & $\begin{array}{r}21,06 \\
5,05 \\
5,57 \\
64,16 \\
4,22 \\
\text { не orp. } \\
0,31 \\
\text { не опр. } \\
0,50\end{array}$ \\
\hline Итого: & 100,18 & 100,42 & 100,76 & 100,37 & 100,87 \\
\hline
\end{tabular}

Модули

\begin{tabular}{l|l|l|l|l|l}
$\mathrm{M}_{\mathrm{o}}$ & 0,92 & 0,96 & 1,11 & 0,85 & 2,16 \\
$\mathrm{M}_{\mathrm{c}}$ & 2,42 & 2,38 & 2,38 & 2,50 & 1,98 \\
$\mathrm{M}_{\mathrm{r}}$ & 1,09 & 1,26 & 1,25 & 1,50 & 0,91
\end{tabular}

Содержание отдельных минералов, \%

Алит $\mathrm{C}_{3} \mathrm{~S}$

Белит $\mathrm{C}_{2} \mathrm{~S}$

Мелилит

мало

\begin{tabular}{|c|c|c|}
$1-2$ & 30 & $\begin{array}{c}3-10 \\
-2\end{array}$ \\
\hline
\end{tabular}

63

19

Тонина помола

\begin{tabular}{|c|c|c|c|c|c|}
\hline $\begin{array}{l}\text { Удельная поверх } \\
\text { ность, } c M^{2} / 2\end{array}$ & 4300 & 6045 & 3830 & 3700 & 3740 \\
\hline $\begin{array}{c}\text { Остаток на сите } \\
\text { № } 90, \%\end{array}$ & 2,3 & 1 & 1,5 & 1,8 & не onp. \\
\hline
\end{tabular}

Примеча.ние: Химические анализы выполнены химиком-аналитиком Х. Силлаве.

* Получен в опытной топке Московского высшего технического училища нм. Баумана. 
Таб.ища 5

Прочность на сжатне образцов из шлакопортланд-цемента при количестве воды затворения $12,25 \%$

\begin{tabular}{|c|c|c|c|c|c|c|c|}
\hline \multirow{3}{*}{ Номер цемента } & \multicolumn{4}{|c|}{ Прочность на } & \multicolumn{3}{|c|}{ с жатие } \\
\hline & \multicolumn{3}{|c|}{ в $\kappa \Gamma / C M^{2}$ в возрасте } & \multirow{2}{*}{$\begin{array}{l}\text { Расчетная } \\
\text { марка } \\
\text { цемента }\end{array}$} & \multicolumn{3}{|c|}{$\begin{array}{c}\text { В \% от 28-дневной } \\
\text { прочнести в возра- } \\
\text { сте }\end{array}$} \\
\hline & 7 дней & 28 дней & 55 дней & & 7 дней & 28 дней & 56 дней \\
\hline $\begin{array}{l}2-15-2^{*} \\
2-15-5 \\
2-15-8 \\
2-25-2 \\
2-25-5 \\
2-25-8 \\
2-40--2 \\
2-40-5 \\
2-40-8\end{array}$ & $\begin{array}{c}75,5 \\
125 \\
139 \\
79.1 \\
115 \\
155 \\
86 \\
135,5 \\
158\end{array}$ & $\begin{array}{l}200 \\
203 \\
213 \\
248 \\
255 \\
234 \\
199 \\
239 \\
220\end{array}$ & $\begin{array}{l}310 \\
281 \\
261 \\
313 \\
307 \\
277 \\
281 \\
339,5 \\
285\end{array}$ & $\begin{array}{l}424 \\
430 \\
451 \\
525 \\
540 \\
495 \\
421 \\
506 \\
466\end{array}$ & $\begin{array}{l}38 \\
62 \\
65 \\
32 \\
45 \\
66 \\
43 \\
57 \\
72\end{array}$ & $\begin{array}{l}100 \\
100 \\
100 \\
100 \\
100 \\
100 \\
100 \\
100 \\
100\end{array}$ & $\begin{array}{l}155 \\
138 \\
123 \\
126 \\
120 \\
118 \\
141 \\
142 \\
129\end{array}$ \\
\hline
\end{tabular}

* Первая цифра - номер шлака, вторая - количество портланд-цемента, третья - количество гипса.

** Получена при умножении прочности в возрасте 28 дней твердения на коэффнциент перехода $\mathrm{K}_{28}=2,12$.

Имея в виду, что из шлака № 2 были получены шлакопортланд-цементы, отвечающие требованиям, предъявляемым к цементам. марки «400», даже с добавкой $15 \%$ клинкера, из остальных трех шлаков изготовлялись шлакопортланд-цементы с этим же содержанием клинкера, но с различным содержанием гипса $(2,5$ и $8 \%$ ). Результаты испытаний даны в табл. 6. На основе этих данных составлены табл. 7 и рис. 1, где приводятся средние относительные прочности шлакопортланд-цемен-

Таблица 6

Прочность на сжатие образцов из различных шлакопортланд-цементов

\begin{tabular}{|c|c|c|c|c|c|c|c|}
\hline \multirow{3}{*}{$\begin{array}{c}\text { Номер } \\
\text { шлакопортланд- } \\
\text { цемента }\end{array}$} & \multicolumn{7}{|c|}{ Прочностьна сжатие } \\
\hline & \multicolumn{3}{|c|}{ в $\kappa \Gamma / C M^{2}$ в. возрасте } & \multirow{2}{*}{$\begin{array}{c}\text { Расчетная } \\
\text { марка } \\
\text { цемента** }\end{array}$} & \multicolumn{3}{|c|}{$\begin{array}{c}\text { В \% от 28-дневной проч- } \\
\text { ности в возрасте }\end{array}$} \\
\hline & 7 дней & 28 дней & 56 дней & & $\mid 7$ дней $\mid$ & 28 дней & 56 дней \\
\hline $\begin{array}{r}\text { MBTY }-15-2 \\
\text { MBTY }-15-5 \\
\text { MBTY-15-8 } \\
1_{4000}-15-2 \\
1_{4000}-15-5 \\
1_{4000}-15-8 \\
1_{6000}-15-2 \\
1_{6000}-15-5 \\
1_{6000}-15-8 \\
4-15-2 \\
4-15-5 \\
4-15-8\end{array}$ & $\begin{array}{c}39,4 \\
62,3 \\
84 \\
63 \\
100 \\
126,5 \\
50,5 \\
100 \\
149 \\
37,4 \\
59.6 \\
86\end{array}$ & $\begin{array}{r}73 \\
87 \\
124 \\
180 \\
162 \\
156 \\
137 \\
202 \\
213 \\
59 \\
85 \\
110\end{array}$ & $\begin{array}{l}100 \\
108 \\
128 \\
248 \\
248 \\
205 \\
335 \\
293 \\
258 \\
112 \\
109 \\
126\end{array}$ & $\begin{array}{l}155 \\
184 \\
263 \\
381 \\
343 \\
331 \\
290 \\
428 \\
451 \\
125 \\
180 \\
233\end{array}$ & $\begin{array}{l}54 \\
72 \\
68 \\
35 \\
62 \\
81 \\
37 \\
50 \\
70 \\
63 \\
70 \\
78\end{array}$ & $\begin{array}{l}100 \\
100 \\
100 \\
100 \\
100 \\
100 \\
100 \\
100 \\
100 \\
100 \\
100 \\
100\end{array}$ & $\begin{array}{l}137 \\
124 \\
103 \\
138 \\
153 \\
131 \\
244 \\
145 \\
121 \\
190 \\
128 \\
114\end{array}$ \\
\hline
\end{tabular}

* Индекс у номера шлака показывает его удельную поверхность.

** Получена при умножении прочности в возрасте 28 дней твердення на коэффициент перехода $\mathrm{K}_{28}=2,12$. 
тов из различных шлаков; прочности через 7,28 и 56 дней твердения указаны в процентах от прочности цементного камня к 28 дню твердения.

Таблица 7

Прочность цементов в процентах от прочности 28-дневного твердения

\begin{tabular}{|c|c|c|c|c|c|}
\hline \multirow{3}{*}{ Вид цемента } & \multicolumn{5}{|c|}{ Прочность в \% в возрасте } \\
\hline & \multicolumn{2}{|l|}{7 дней } & \multirow[b]{2}{*}{28 дней } & \multicolumn{2}{|c|}{56 дней } \\
\hline & $\begin{array}{l}\text { предельные } \\
\text { значения }\end{array}$ & $\begin{array}{l}\text { сред- } \\
\text { нее }\end{array}$ & & $\begin{array}{c}\text { предельные } \\
\text { значения }\end{array}$ & $\begin{array}{c}\text { сред- } \\
\text { нее }\end{array}$ \\
\hline Шлакопортланд-цементы * & & & & & \\
\hline $\begin{array}{l}\text { а) с } 2 \% \text { гипса } \\
\text { б) с } 5 \% \text { гипса } \\
\text { в) с } 8 \% \text { гипса }\end{array}$ & $\begin{array}{l}35-63 \\
50-72 \\
65-81\end{array}$ & $\begin{array}{l}45 \\
63 \\
72\end{array}$ & $\begin{array}{l}100 \\
100 \\
100\end{array}$ & $\begin{array}{l}137-244 \\
128-153 \\
103-131\end{array}$ & $\begin{array}{l}173 \\
138 \\
118\end{array}$ \\
\hline $\begin{array}{l}\text { Портланд-цементы ПЦ-1 } \\
\text { и ПЦ-2 }\end{array}$ & $62,5-64$ & 63 & 100 & 一 & - \\
\hline
\end{tabular}

* Испытывалось пять различных составов шлака.

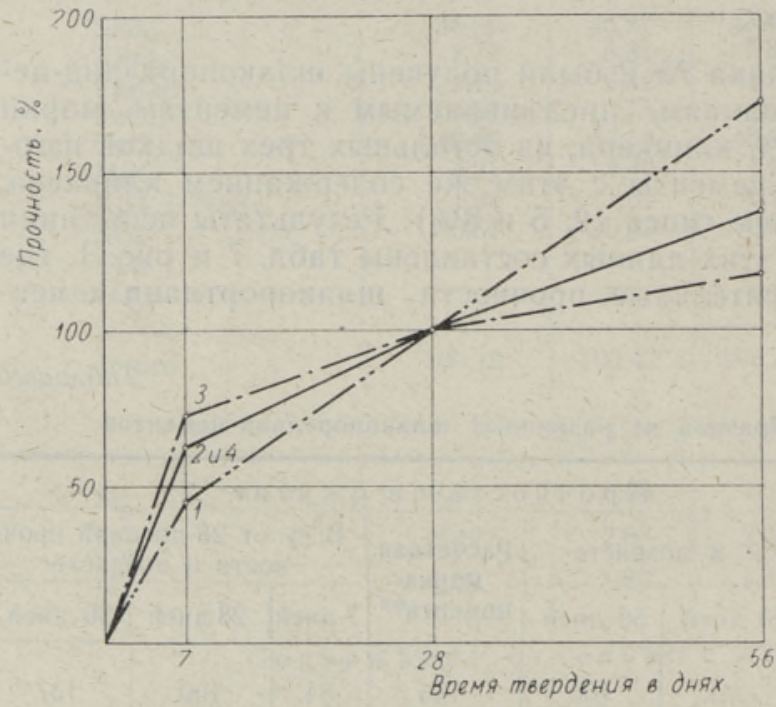

Рис. 1. Прочность портланд-цемента и шлакопортланд-цементов с добавкой $15 \%$ клинкера в прсцентах от их прочности в 28-дневном возрасте. Шлакопортланд-цемент: 1 - с $2 \%$ гипса; 2 - с $5 \%$ гипса; $3 \ldots$ с $8 \%$ гипса; 4 - портландцемент.

Данные опытов показывают, что увеличение содержания двуводного гипса в шлакопортландцементе значительно повышает их прочность на сжатие к 7 дню твердения. но вызывает после 28 лней у активных шлакоз (№ 1, 2) более медленное нара-

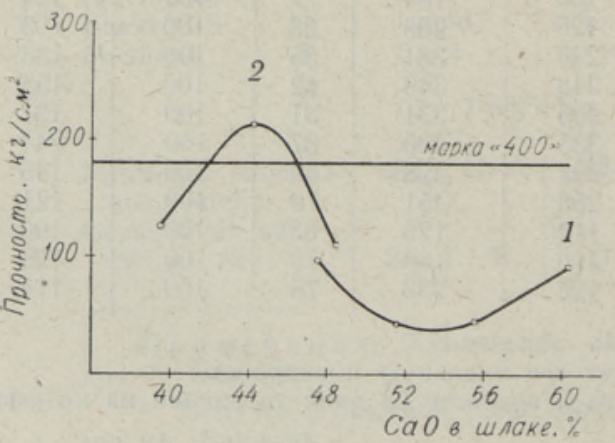
стание прочности. При этом уже $5 \%$-ная добавка гипса обеспечивает получение шлакопортландцементов, у которых нарастание прочности во времени совпадает с таковым у портланд-цемента. Повышение количества гипса до $8 \%$

Рис. 2. ІІрочность шлакопортланд-цементов в 28-днезном возрасте. 1 - шлакопортланд-цемент с $20 \%$ клинкера; 2 шлакопортланд-цемент с 15\% клинкера и $8 \%$ гипса. 
увеличивает марочную прочность цемента (к 28 дню твердения). Как следует из диаграммы «Содержание $\mathrm{CaO}$ в шлаке - прочность на сжатие» (рис, 2), наиболее активными при нормальном твердении являлись слабокислые шлаки, содержащие примерно $42,5-46 \% \mathrm{CaO}$. Из них можно получить хорошие шлакопортланд-цементы марки « $400 »$ с добавкой лишь $15 \%$ клинкера в присутствии $5-8 \%$ гипса.

\section{4. Гидротермальная обработка сланцезольных шлаков}

Исходя из химического состава сланцезольных шлаков можно было предположить, что для них не менее перспективна автоклавная обработка, так как они содержат мало глинозема, который значительно повынает активность шлаков при нормальном твердении, но нежелателен при гидротермальной обработке. Для выяснения возможностей использования сланцезольных шлаков для производства автоклавного бетона были проведены опыты по обработке шлаков № $3,5,6,7$ и ИЭ (составы в табл. 2) в автоклаве. В качестве добавок применялись двуводный гипс и гашеная известь, содержащая $71 \%$ активной окиси кальция (по ГОСТ 1175-51). Кубики изготовлялись пластичным методом из раствора $(1: 3)$.

В связи с тем, что в автоклавных бетонах из силикатных минералов наибольшую прочность имеют низкоосновные гидросиликаты кальция, желательно, чтобы при гидротермальной обработке шлаков образовывались именно эти соединения.. Для того чтобы белит, кристаллизовавшийся в исследованных шлаках, при автоклавной обработке реагировал с кремнеземом до моносиликата кальция, надо обеспечить достаточную поверхность зерен добавленного песка. Для этого часть (25\%) вводимого в раствор песка измельчалась до удельной поверхности $3150 \mathrm{~cm} 2 / 2$. Автоклавная обработка проводилась через $18-20$ часов после формования. Режим обработки: 12 ати, $2,5+4+1,25$ час. Образцы извлекались из форм сразу после обработки в автоклаве, а через 3 дня испытывались на прочность (табл. 8 , рис. 3 ).

Таблица 8

Прочность автоклавных образцов на сжатие

\begin{tabular}{|c|c|c|c|}
\hline $\begin{array}{l}\text { Номер } \\
\text { шлака }\end{array}$ & Добавка & $\left|\begin{array}{c}\text { Количест- } \\
\text { во воды } \\
\text { затворе- } \\
\text { ния, \% }\end{array}\right|$ & $\begin{array}{c}\text { Прочность на } \\
\text { сжатие, } \\
\kappa \Gamma / C \mu^{2}\end{array}$ \\
\hline $\begin{array}{c}\text { H3 } \\
3 \\
5 \\
6 \\
7\end{array}$ & $\frac{-}{-}+$ & $\begin{array}{l}13,5 \\
14,5 \\
14,5 \\
15,5 \\
20,0\end{array}$ & $\begin{array}{l}0,95 \\
13 \\
571 \\
579 \\
270\end{array}$ \\
\hline $\begin{array}{l}3 \\
5 \\
6 \\
7\end{array}$ & $\begin{array}{lc}5 \% & \mathrm{CaSO}_{4} \cdot 2 \mathrm{H}_{2} \mathrm{O} \\
5 \% & ", \\
5 \% & " \\
5 \% & ",\end{array}$ & $\begin{array}{l}14,5 \\
14,5 \\
15,5 \\
20,0\end{array}$ & $\begin{array}{r}14 \\
17 \\
355 \\
357\end{array}$ \\
\hline $\begin{array}{c}13 \\
3 \\
5 \\
6 \\
7\end{array}$ & $\begin{array}{lc}5 \% & \mathrm{Ca}(\mathrm{OH})_{2} \\
5 \% & , \\
5 \% & , \\
5 \% & , \\
5 \% & ,\end{array}$ & $\begin{array}{l}13,5 \\
14,5 \\
14,5 \\
15,5 \\
20,0\end{array}$ & $\begin{array}{r}41 \\
398 \\
387 \\
309 \\
294\end{array}$ \\
\hline
\end{tabular}


Из приведенных данных следует, что прочность на сжатие автоклавных образцов сильно зависит от химического состава шілака и имеет

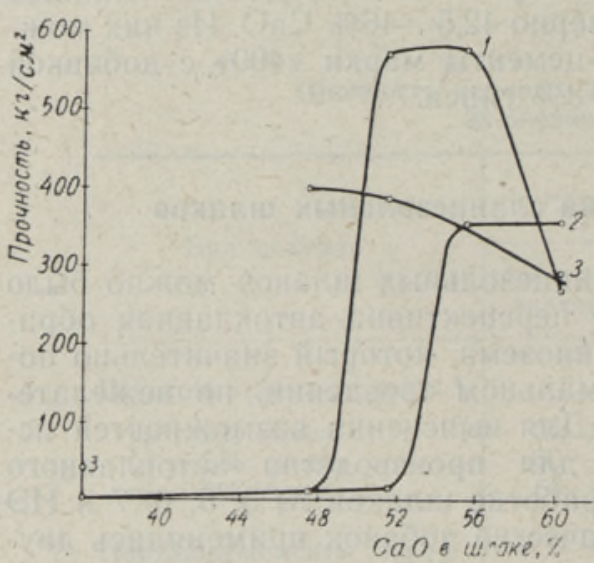

Рис. 3. Прочность шлаковых цементов прн автоклавной обработке. Шлак: 1 без добавок; $2-+5 \%$ гипса; $3-$ $+5 \%$ гашеной извести. у образцов, изготовленных без добавок, максимальную величину при содержании в шлаке $50-58 \% \mathrm{CaO}$.

Добавление $5 \%$ гашеной извести к шлаковому вяжущему повышало прочность только тех образцов, которые были изготовлены из шлаков, содержащих менее $50 \% \mathrm{CaO}$. При этом не было достигнуто такой прочности, как у образцов из шлаков № 5 и № 6 (51,5 и 55,5\% CaO) без добавок. Добавка извести к более основным шлакам влияла отрицательно. Несмотря на то, что обшее содержание окиси кальция в цементах, изготовленных из шлаков без добавки извести (№ 5,6$)$ и с добавкой ее $(№ 3,5)$, почти одинаково, прочность последних оказывается значительно меньшей. Следовательно, окись кальция из добавленной из. вести и содержащаяся в шлаке реагирует при автоклавной обработке неөдинаково. В противном случае кривая 3 (рис. 3) должна быть аналогичной кривой 1 , но сдвинутой на $3,53 \%$ в сторону более основнь!x шлаков.

Прочность образцов с добавкой $5 \%$ двуводного гипса изменялась своеобразно. При содержании $\mathrm{CaO}$ в шлаке менее $52 \%$ образцы практически прочности не имели. При этом и те образцы, которые без добавки гипса имели высокую прочность, теряли ее. Далее, в шлаках, содержащих около $53 \%$ окиси кальция, прочность образцов резко повышалась, но не достигала прочности образцов без добавок. При еще большем увеличении содержания окиси кальция в шлаках, вплоть до $60 \%$, прочность образцов оставалась без изменения.

Следовательно, при автоклавной обработке основных шлаков, содержащих более $50 \% \mathrm{CaO}$, добавка гипса или извести не вызывает дополнительного повышения прочности.

Нужно подчеркнуть, что приведенные данные получены для смесей, содержащих одинаковое количество измельченного песка, размалывавшегося во всех случаях до одной и той же тонины. Вероятно, что при более точной дозировке измельченного песка в соответствии с составом шлака могут быть получены цементы, обладающие еще большей прочностью.

Сопоставляя данные прочности шлакопортланд-цементов с минералогическим составом исходных шлаков, можно утверждать, что стекловидные шлаки пригодны для щелочной активизации при нормальных условиях твердения, т. е. для производства шлакопортланд-цемента. Для шлаков, содержащих более $30 \%$ белита,. выгоднее автоклавная обработка.

* Добавлено $5 \%$ гашеной нзвести с активностью 0,71 . 


\section{5. Температура жидкотекучего состояния сланцезольных шлаков}

Температура жидкотекучего состояния шлаков является важной характеристикой для оценки возможности технического и экономического осушествления жидкого шлакоудаления при сжигании топлив. Средние температуры жидкотекучего состояния сланцезольных шлаков даны в табл. 9 и на рис. 4.

\section{Таблица 9}

\section{Температуры жидкотекучего состояния} шлаков

\begin{tabular}{c|c|c}
\hline $\begin{array}{c}\text { Номер } \\
\text { шлака }\end{array}$ & $\begin{array}{c}\text { Содержание } \\
\text { СаО, \% }\end{array}$ & $\begin{array}{c}\text { Темпера- } \\
\text { тура жидко- } \\
\text { текучего co- } \\
\text { стояния, }\end{array}$ \\
\hline & & \\
\hline 1 & 42,65 & 1450 \\
2 & 44,18 & 1500 \\
3 & 47,47 & 1540 \\
4 & 48,35 & 1550 \\
5 & 51,5 & 1750 \\
6 & 55,5 & 1810 \\
7 & 60,3 & 1820 \\
& &
\end{tabular}

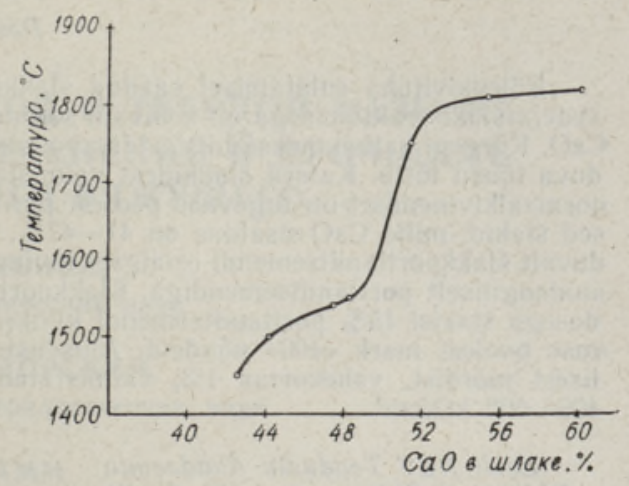

Рис. 4. Нзменение температуры жидкотекучего состояния в зависимости от состава шлака.

113 рис. 4 видно, что с точки зрения жидкотекучести шлаков повышение содержания окиси кальция в них выше 49\% нежелательно, так как каждый следуюший процент $\mathrm{CaO}$ повышает температуру жидкотекучего состояния примерно на $75^{\circ} \mathrm{C}$. Поэтому для осушествления жидкого шлакоудаления наиболее пригодными являются шлаки с содержанием окиси кальция ниже $49 \%$, которые к тому же оказываются наиболее подходящими для производства шлакопортланд-цемента.

\section{Выводы}

1. Наиболее пригодными для жидкого шлакоудаления следует считать сланцезольные шлаки, содержащие не более $49 \%$ окиси кальция, так как при дальнейшем увеличении содержания окиси кальция температура жицкотекучего состояния шлака резко псвышается.

2. Наиболее подходящими для изготовления шлакопортланд-цементов, твердеющих при нормальных условиях, являются стекловидные кислые или нейтральные шлаки, содержащие $41-47 \% \mathrm{CaO}$ (модуль основности $\left.\mathrm{M}_{0}=0,88-1,05\right)$.

3. Введение в состав сланцезольных шлакопортланд-цементов небольших количеств гипса значительно повышает их прочность в начальные сроки твердения, но уменьшает последующее увеличение (после 28 дней) прочности.

4. Из шлаков, содержащих $42,5-46 \% \mathrm{CaO}$, с добавкой $5-8 \%$ гипса и $15 \%$ клинкера, можно получать шлакопортланд-цементы, марка которых равна или превышает марку использованного портланд-цемента, а характер нарастания прочности со временем аналогичен таковому у портланд-цемента.

5. При автоклавной обработке цемен์тного раствора, содержащего. $20 \%$ измельченного песка, наибольшую прочность дают основные щлаки, содержащие $50-58 \% \mathrm{CaO}\left(\mathrm{M}_{0}=1,15-1,60\right)$. Ннститут строительства и строительных материалов
Академии наук Эстонской ССР
Поступила в редакцию

9. VI 1962 


\title{
PŌLEVKIVISLAKKIDE KASUTAMISEST EHITUSSIDEAINENA
}

\author{
J. Lasn
}

\section{N. Dilaktorski,}

geoloogia-mineraloogiateaduste doktor

\section{Resümee}

Pōlevkivituha sulatamisel saadud šlakkide uurimine näitas, et pōlevkivi pōletamiseks vedela šlaki eraldamisega on sobivam selline kütus, millest tekkiv šlakk sisaldab alla $49 \%$ $\mathrm{CaO}$. Kōrgem kaltsiumoksüüdisisaldus pole soovitatav šlaki vedelvoolavustemperatuuri tunduva tôusu tôttu. Katsed šlakkidest valmistatud šlakkportlandtsementidega näitasid, et ka normaalkivinemisel on tugevuse poolest parimad klaasjad, nōrgalt happelised vōi neutraalsed šlakid, mille $\mathrm{CaO}$-sisaldus on $41-47 \%$. Kipsi lisandamine- $5-8 \%$ ulatuses tōstab tunduvalt šlakkportlandtsemendi esialgset kivinemise kiirust ja kindlustab tema tugevuse kasviı analoogiliselt portlandtsemendiga. Slakkportlandtsement, mis saadi $42,5-46 \% \mathrm{CaO}$ sisaldusega šlakist $15 \%$ portlandtsemendi klinkri ja $5-8 \%$ kipsi lisandamisega, rahuldas tugevuse poolest mark «400» nōudeid. Aluseliste šlakkide (CaO-sisaldusega $51-58 \%$ ) plastilisest mördist, vahekorras 1:3, valmistatud autoklaavitud katsekehade survetugevus oli $400-600 \mathrm{kG} / \mathrm{cm}^{2}$.

Eesti NSV Teaduste Akadeemia Ehituse ja Ehitusmaterjalide Instituut
Saabus toimetusse

9. VI 1962

\section{UTILIZATION OF COMBUSTIBLE SHALE ASH SLAGS FOR PRODUCING BINDING MATERIALS FOR BUILDING}

\section{J. Lasn, N. Dilaktorski}

\section{Summary}

The slags produced by melting combustible shale ash have been studied. It was found that combustible shales, which yield slag with a $\mathrm{CaO}$ content of less than $49 \%$, were more suitable for burning with a separation of slag in a liquid state. The rising of the $\mathrm{CaO}$ content in slag to more than $49 \%$ is undesirable as it is accompanied by a considerab!e rise of temperature in a fluid state. At hardening of slag Portland cement in normal conditions, the best compressive strength was also received with glassy acid or neutral slags $(41-47 \% \mathrm{CaO})$. An addition of $5-8 \%$ gypsum raised the rate of strength development and made it similar to that of Portland cement. The strength of slag Portland cement prepared from slag $(42.5-46 \% \mathrm{CaO})$ with $15 \%$ of Portland cement clinker and $5-8 \%$ of gypsum corresponds to that of cement brand "400". The strength of autoclaved test cubes prepared from plastic mortars of alkaline slags $(51-58 \% \mathrm{CaO})$ was $400-600 \mathrm{kG}$ per square $\mathrm{cm}$.

Academy of Sciences of the Estonian S.S.R.,

Received

Institute of Building and Buitding Materials 